\title{
Original
}

\section{Main symptoms associated with the catastrophizing in women with fibromyalgia and migraine}

\author{
Amanda de Oliveira Freire Barros ${ }^{1}$ (D) Manuella Moraes Monteiro Barbosa Barros ${ }^{2}$ iD Reydiane Rodrigues \\ Santana ${ }^{2}$ iD Débora Wanderley ${ }^{1}$ (D) Angélica da Silva Tenório ${ }^{1}$ (D) Daniella Araújo de Oliveira1 ${ }^{1}$
}

${ }^{1}$ Physical Therapy Department, Universidade Federal de Pernambuco, Recife, Pernambuco, Brazil.

${ }^{2}$ Post-graduation Program in Neuropsychiatry and Behavioral Sciences, Universidade Federal de Pernambuco, Recife, Pernambuco, Brazil.

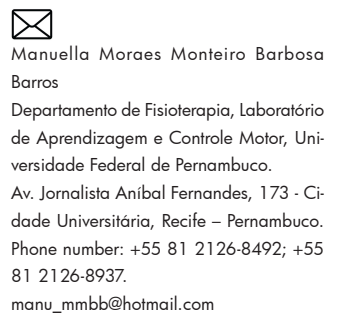

Edited by

Marcelo Moraes Valença

Keywords:

Fibromyalgia

Migraine disorders

Catastrophization

Sleep

Depression

Anxiety Disorders

Quality of life

Disability

Exercise

\begin{abstract}
Objective

To evaluate the main symptoms associated with catastrophizing in women with fibromyalgia and migraine.

Methods

We conducted an observational study with 26 women diagnosed with both fibromyalgia and migraine, aged between 30 and 60 yrs ( $46 \pm 8$ yrs). The Pain Catastrophizing Scale was applied as a cut-off point of 30 , dividing the volunteers into groups with $(n=18)$ and without catastrophizing $(n=8)$. We assessed the quality of sleep (Pittsburgh Sleep Quality Index), the presence of depression and anxiety (Beck's Depression and Anxiety Inventories), the quality of life perception (Fibromyalgia Impact Questionnaire-revised), the disability due to migraine (Migraine Disability Assessment), and the level of physical activity (International Physical Activity Questionnaire).

\section{Results}

The time of fibromyalgia did not differ $(p=0.80)$ between the group with $(8.54 \pm 4.88 \mathrm{yrs})$ and without catastrophizing (10.04 $\pm 3.47 \mathrm{yrs})$. The Fibromyalgia Impact Questionnaire-revised scores were significantly higher $(p=0.01)$ among women with catastrophizing $(78.0 \pm 12.6)$ than those without $(56.6 \pm 22.3)$. There was no difference between the groups $(p>0.05)$ in relation to the other outcomes evaluated.

\section{Conclusion}

The presence of catastrophizing in women with fibromyalgia and migraine are associated with a worse perception of quality of life.
\end{abstract}




\section{Introduction}

- ibromyalgia is a a broad-spectrum disease that has an average worldwide prevalence of $4.1 \%$ in women.' Over the years, the classification of fibromyalgia by the American College of Rheumatology has undergone improvements, ceasing to be characterized only by chronic widespread pain and the presence of tender points in anatomically specific regions, known as tender points. ${ }^{2}$ Currently the classification takes into account the symptoms associated with this disease. ${ }^{3,4}$

The etiology of fibromyalgia is not yet fully understood, but several factors contribute to its development, including dysfunctions of the central and autonomic nervous system, neuroendocrine disorders, regulation of neurotransmitters, changes in the hypothalamic-pituitary axis, and exposure to stressors. 5,6 Sensory stimuli transmitted to the central nervous system are processed in an altered manner, resulting in generalized pain and changes in the painful threshold.., 7

Fibromyalgia presents a complex picture that includes numerous symptoms such as depression, anxiety, headache, cognitive, and sleep disorders and negative impacts on quality of life. ${ }^{8}$ In this context, migraine is a relevant symptom and represents the type of headache most found in patients with fibromyalgia, whose prevalence varies between $45 \%$ and $80 \%$.

In addition, the cognitive and emotional aspects related to the pain experienced by fibromyalgia patients involve a catastrophizing thought, recognized as a negative state in the face of a painful experience. ${ }^{10}$ Depression is part of the factors that interfere with the painful perception of fibromyalgia, but unlike catastrophization, it refers to sadness, discouragement, lack of interest, and unwillingness to perform activities that previously gave you pleasure. In turn, catastrophizing is specifically related to thoughts and feelings linked to the painful situation, such as fear, worry, inability to divert attention, and deal with pain. ${ }^{11}$

There is still a lack of studies in the literature ${ }^{12-15}$ evaluating the presence of catastrophization however, it is known that this symptom is related to chronic pain, feelings of incapacity, ${ }^{12}$ more severe degrees of depression and anxiety, more migraine attacks, ${ }^{13}$ exercise intolerance ${ }^{14}$ and sleep disorders ${ }^{15}$. Also, catastrophization can worsen the perception of these symptoms, which are also present in fibromyalgia and migraine, making it necessary to evaluate them to guide the treatment of patients.

Despite the above, the catastrophization of pain has not yet been analyzed in women with associated fibromyalgia and migraine. Thus, the present study aimed to assess the main symptoms associated with catastrophization in women with fibromyalgia and migraine.

\section{Methods}

This is an observational, cross-sectional study. The research was carried out from March to November 2015, at the school clinic of the Physiotherapy Department of the Federal University of Pernambuco (UFPE), Recife, Pernambuco, Brazil. The research was approved by the Human Research Ethics Committee of the Health Sciences Center of UFPE (CAAE 37052114.3.0000.5208). All participants signed an informed consent form.

\section{Sample}

The participants were recruited from the list of patients seen at the fibromyalgia outpatient clinic of the rheumatology sector at Hospital das Clínicas, UFPE. Patients who met the following inclusion criteria were selected: 1. having a diagnosis of fibromyalgia and migraine, simultaneously; and 2 . age between 30 and 60 years. Pregnant women were excluded due to hormonal changes and their relationship with the presence of migraine, and obese participants.

\section{Procedures for data collection}

By phone, the participants were invited to participate in the survey and asked about the eligibility criteria. In the initial evaluation, a semi-structured questionnaire was applied to obtain sociodemographic and clinical data. Then, they went through the evaluation of a neurologist who diagnosed the type of headache, based on the criteria of the International Classification of Headache Disorders, $3^{\text {rd }}$ edition - beta version. ${ }^{16}$

The presence of catastrophizing was assessed using the pain catastrophizing scale. This instrument, validated and adapted to Portuguese (Cronbach alpha= 0.91), assesses the thoughts and feelings of the volunteers in the face of pain experience and consists of 13 items, whose score ranges from $0-4$, with 52 being the maximum score..$^{7}$ The global score of 30 indicates that the individual has clinically relevant levels of catastrophization. ${ }^{18}$ The sample was then divided into two groups, one with catastrophization and one without.

\section{Outcome Assessment}

The sleep quality outcome was assessed using the Pittsburgh Sleep Quality Index (PSQI), validated and adapted for the Brazilian population, with high reliability (Cronbach $a=0.82$ ). The PSQI has 19 questions ranging from 0-3 and is divided into seven components related to sleep: subjective quality, latency, duration, habitual efficiency, changes and the use of sleep medications, and daytime dysfunction. The total score was given by the sum of all components, reaching a maximum of 21 points. ${ }^{19}$

The depression outcome was assessed by Beck Depression Inventory (BDI), an instrument consisting of 21 multiple-choice questions ranging from 0-3 points, reaching a maximum total score of 63. From the score obtained, the participants were classified as absence (0-9 
points), mild depression (10-18 points), moderate (19-29 points), and severe ( $>30$ points). BDI is validated and adapted for the Brazilian population (Cronbach $a=0.81$ ). ${ }^{20,21}$ Anxiety was assessed by the Beck Anxiety Inventory (BAI), which is also validated and adapted for the Brazilian population. Composed of 23 multiple-choice questions (ranges from 0-4), the total score was achieved by the sum of all items, reaching a maximum of 63 points, generating the classification: minimal anxiety (0-10 points), mild (11-19 points), moderate (20-30 points) and severe (> 31 points). ${ }^{22}$

The impact of fibromyalgia on the quality of life of the volunteers was measured by Fibromyalgia Impact Questionnaire-Revised (FI$\mathrm{Q}-\mathrm{R})$, with validation and adaptation for the Brazilian population (Cronbach's alpha of 0.96). The instrument contains 21 questions that can vary from 0-10, with 100 being the maximum score. The FIQ-R is divided into three domains: function, global impact, and symptom intensity. The final score was given by the sum of these and the higher, the greater the impact of fibromyalgia on quality of life. The level of pain resulting from fibromyalgia was assessed using this questionnaire, which presents a specific scale related to pain, whose domain of symptom intensity varies from zero to ten. ${ }^{23}$

Migraine disability was assessed by the Migraine Disability Assessment Test (MIDAS). From the sum of the scores, the volunteers were classified as minimal disability (0-5 points), mild (6-10 points), moderate (11-20 points), and severe (> 20 points). ${ }^{24}$

The level of physical activity was verified by the International Physical Activity Questionnaire (IPAQ), in its short version. It consists of four questions containing two sub-items that allowed measuring the frequency, duration of activities, intensity during the week, and also the periods of inactivity of the participants. Among the categories provided by IPAQ, it was possible to classify the volunteers as very active, active, irregularly active and sedentary, through data related to the frequency and duration reported by them. ${ }^{25}$

\section{Statistical Analysis}

The data were analyzed using the Statistical Package for Social Sciences (SPSS) version 22.0. A descriptive analysis was performed with a calculation of the standard deviation for the averages of the measurement variables and frequency of the other variables that characterize the sample. To test the normality of the variables, the Shapiro-Wilk test was used. The Student t-test was used for variables with normal distribution and the Mann-Whitney test for variables with non-normal distribution. In the analysis of categorical variables, the chi-square test $\left(\chi^{2}\right)$ was applied. The level of significance considered was $\mathrm{p}<0.05$.

\section{Results}

Of the 29 women evaluated, one was excluded for having another type of headache and two for not completing the questionnaires. The general characterization of the sample of the 26 included participants (45.9 \pm 7.9 years) and the clinical level of pain catastrophization is shown in Table 1. There was no difference between the groups regarding the time of diagnosis of fibromyalgia.

Table 2 shows the characteristics of the sample in relation to the associated symptoms. The presence of migraines had a serious impact on the daily and professional life of half of the sample. When observing the psychological characteristics of the studied population, it was possible to identify that $76.93 \%$ of the volunteers had a degree of depression from mild to moderate and $65.39 \%$ reported a moderate to severe degree of anxiety.

Fibromyalgia Impact Questionnaire-Revised scores were significantly higher $(p=0.01)$ among women with catastrophization (78.0 \pm 12.6$)$ than those without $(56.6 \pm 22.3)$. There was no difference between groups ( $p>0.05$ ) in relation to the other outcomes assessed (Table 2).

\section{Discussion}

In the present study, only the perception of quality of life was associated with the presence of catastrophization in women with fibromyalgia and migraine. Despite the lack of association in relation to the other outcomes studied, the results of our study are of great clinical relevance, as they demonstrate that catastrophization can worsen the perception of function, global impact, and intensity of symptoms in patients with fibromyalgia and migraine, generating negative repercussions in the quality of life of this population. In addition, this is a pioneering study, since the catastrophizing of pain has not yet been analyzed in women with associated fibromyalgia and migraine.

In the present study, more than half of women with fibromyalgia and migraine exhibited clinically relevant levels of pain catastrophization, differing from the results of another study ${ }^{13}$, in which only a quarter of the sample, composed of migrant women, presented this symptom. In this way, it is possible that the presence of associated fibromyalgia and migraine, which share similar pathophysiological pathways ${ }^{7,10}$, has contributed to greater susceptibility to pain, potentiating changes in central processing and generating greater impact on catastrophizing symptoms.

Another relevant aspect, frequently cited in the literature, is that catastrophization provides a more intense experience of pain in patients with chronic pain. ${ }^{14}$ For this reason, women with the presence of associated fibromyalgia and migraine were expected to experience greater pain intensity and changes in pain threshold. ${ }^{6,7}$ Despite this, in our study, no great variations were observed in the intensity of pain due to migraine and fibromyalgia.

On the other hand, our study showed that fibromyalgia and migraine women with catastrophization had greater impacts on the perception of quality of life. It is known that both fibromyalgia ${ }^{8}$ and migraine ${ }^{26}$ promote negative impacts on patients' quality of life. Thus, the associ- 
ation between different disabling clinical conditions could aggravate catastrophizing symptoms, making it difficult for the patient to deal with the painful situation."

It is also often cited that women with fibromyalgia are less physically active than healthy women ${ }^{27}$, which could be explained by the fear that fibromyalgia patients have that physical activity could worsen their symptoms. ${ }^{28}$ In addition, people with high levels of catastrophization may have worse physical performance ${ }^{14}$, probably due to intolerance to pain-related activity.

Another common association is the presence of catastrophization, sleep disorders ${ }^{15}$, and more severe degrees of depression and anxiety. ${ }^{13}$ Despite the findings, in our study the catastrophizing group did not present lower levels of physical activity and no association was observed with worsening migraine impact, sleep disorders, depression, and anxiety. It is possible that the lack of association between the variables studied in the present research is related to the small sample size.

The results of the present study have some limitations. As it is an observational study, it is not possible to establish cause-and-effect relationships in this research. In addition, the small sample size makes it impossible to perform statistical analysis with multiple linear regression, which would make it possible to verify the influence of dependent variables with catastrophization.

Table 1. Characterization of the sample with and without the clinical level of catastrophization.

\begin{tabular}{|c|c|c|c|c|}
\hline \multirow{2}{*}{ Variables } & \multirow{2}{*}{$\begin{array}{l}\text { Total sample (n } \\
=26 \text { ) }\end{array}$} & \multicolumn{2}{|c|}{ Catastrophizing } & \multirow{2}{*}{$p^{*}$} \\
\hline & & With $(n=18)$ & $\begin{array}{l}\text { Without } \\
(\mathrm{n}=8)\end{array}$ & \\
\hline Age (years) & $45.92 \pm 7.88$ & $47.11 \pm 7.79$ & $43.25 \pm 7.9$ & 0.17 \\
\hline BMI $\left(\mathrm{Kg} / \mathrm{m}^{2}\right)$ & $27.97 \pm 4.94$ & $28.09 \pm 4.92$ & $27.7 \pm 5.32$ & 1.00 \\
\hline $\begin{array}{l}\text { Time of medication } \\
\text { (years) }\end{array}$ & $3.95 \pm 2.52$ & $4.05 \pm 2.51$ & $3.62 \pm 2.93$ & 0.85 \\
\hline $\begin{array}{l}\text { Time diagnosis of } \\
\text { fibromyalgia (years) }\end{array}$ & $7.42 \pm 8.65$ & $8.54 \pm 10.04$ & $4.88 \pm 3.47$ & 0.80 \\
\hline \multicolumn{5}{|l|}{ Race n(\%) } \\
\hline White & $9 / 26(34.6)$ & $5 / 26(27.7)$ & 4/8 (50) & \\
\hline Brown & $13 / 26(50.0)$ & $11 / 26(61.1)$ & 2/8 (25) & \\
\hline Black & $4 / 26(15.3)$ & $2 / 18$ (11.1) & 2/8 (25) & \\
\hline \multicolumn{5}{|l|}{ Marital status $\mathrm{n}(\%)$} \\
\hline Single & $11 / 26(42.3)$ & $9 / 18(50.0)$ & $2 / 8(25.0)$ & \\
\hline Married & $12 / 26(46.1)$ & 7/18 (38.8) & $5 / 8(62.5)$ & \\
\hline Divorced & $3 / 26(11.5)$ & $2 / 18(11.1)$ & 1/8 (12.5) & \\
\hline
\end{tabular}

*Student t-test.

Data are presented as mean \pm standard deviation or $\mathrm{n}(\%)$. BMI - Body Mass Index.
Table 2. Characterization of the sample with and without the clinical level of catastrophization.

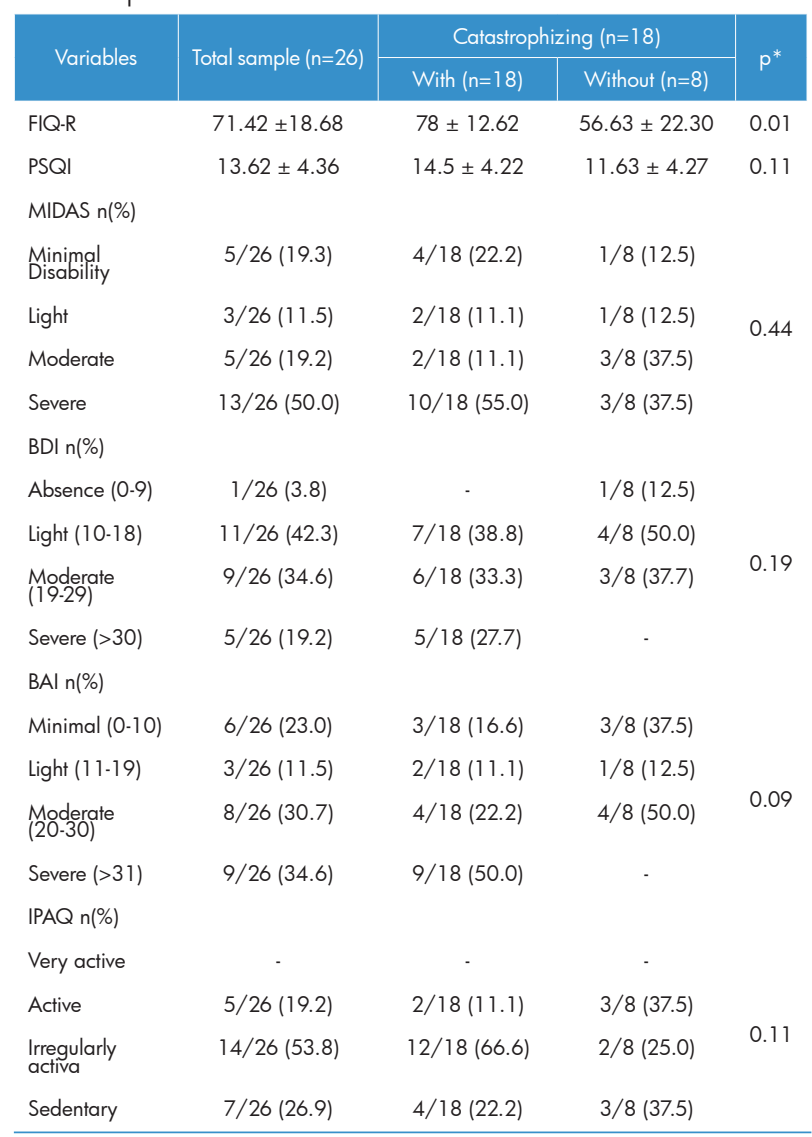

* $\times 2$ Test.Data are presented as mean \pm standard deviation or $n=$ number of patients and (\%). FIQ-R - Fibromyalgia Impact Questionnaire-Revised; PSQI - Pittsburgh Sleep Quality Index; MIDAS - Migraine Disability Assessment Test; BDI - Beck Depression Inventory; BAI - Beck Anxiety Inventory; IPAQ - International Physical Activity Questionnaire.

\section{Conclusion}

The presence of catastrophization in women with fibromyalgia and migraine is associated with a worsening perception of quality of life.

The authors declare that there is no conflict of interest

Place where the study was conducted: Departamento de Fisioterapia, Laboratório de Aprendizagem e Controle Motor, Universidade Federal de Pernambuco.

The research was approved by the Comitê de ética em pesquisa com seres humanos do Centro de Ciências da Saúde from - UFPE (CAAE 37052114.3.0000.5208). 


\section{References}

1. Queiroz LP. Worldwide epidemiology of fibromyalgia topical collection on fibromyalgia. Curr Pain Headache Rep. 2013; 17: 356.

2. Wolfe F, Smythe HA, Yunus MB, et al. The American College of Rheumatology 1990 Criteria for the Classification of Fibromyalgia. Report of the Multicenter Criteria Committee. Arthritis Rheum. 1990; 33: 160-72.

3. Wolfe F, Clauw DJ, Fitzcharles MA, et al. The American College of Rheumatology preliminary diagnostic criteria for fibromyalgia and measurement of symptom severity. Arthritis Care Res. 2010;62: 600-10.

4. Wolfe F. New American College of Rheumatology criteria for fibromyalgia: A twenty-year journey. Arthritis Care Res. 2010; 62: 583-4.

5. Bellato $E$, Marini E, Castoldi F, et al. Fibromyalgia syndrome: etiology, pathogenesis, diagnosis, and treatment. Pain Res Treat. 2012; 2012: 1-17.

6. Silva LC, Oliveira DA, Martins HAL, et al. Fibromigrânea: uma nova denominação para uma velha doença? Headache Med. 2011; 2: 89-95.

7. Valença MM, Medeiros FL, Martins HA, et al. Neuroendocrine dysfunction in fibromyalgia and migraine. Curr Pain Headache Rep. 2009; 13: 358-64.

8. Arnold LM, Croord LJ, Mease PJ, et al. Patient perspectives on the impact ofifbromyalgia. Patient Educ Couns. 2008; 73: 1 14-20.

9. Stuginski-barbosa J, Dach F, Speciali JG. Relação entre cefaleia primária e fibromialgia: revisão de literatura. Rev Bras Reumatol. 2007; 47: 114-20.

10. Sullivan MJ, Thorn B, Haythornthwaite JA, et al. Theoretical perspectives on the relation between catastrophizing and pain. Clin J Pain. 2001; 17: 52-64.

11. Edwards RR, Cahalan C, Mensing G, et al. Pain, catastrophizing, and depression in the rheumatic diseases. Nat Rev Rheumatol. 2011; 7: 216-24.

12. Severeijns R, Vlaeyen JW, van den Hout Ma, et al. Pain catastrophizing predicts pain intensity, disability, and psychological distress independent of the level of physical impairment. Clin J Pain. 2001; 17: 165-72.

13. Bond DS, Buse DC, Lipton RB, et al. Clinical pain catastrophizing in women with migraine and obesity. Headache. 2015; 57: 923-33.

14. Sullivan MJL, Rodgers WM, Wilson PM, et al. An experimental investigation of the relation between catastrophizing and activity intolerance. Pain. 2002; 100: 47-53.
15. Buenaver LF, Quartana PJ, Grace EG, et al. Evidence for indirect effects of pain catastrophizing on clinical pain among myofascial temporomandibular disorder participants: The mediating role of sleep disturbance. Pain. 2012; 153: 1159-66.

16. Headache Classification Committee of the International Headache Society. The international classification of headache disorders. Cephalalgia. 2013; 33: 629-808.

17. Sehn F, Chachamovich E, Vidor LP, et al. Cross-Cultural adaptation and validation of the brazilian portuguese version of the pain. Pain Med. 2012; 13: 1425- 35.

18. Sullivan M, Bishop S, Pivik J. The pain catastrophizing scale: development and validation. Psychol Assess. 1995; 7: 524-32.

19. Bertolazi AN, Fagondes SC, Ho LS, et al. Validation of the Brazilian Portuguese version of the Pittsburgh Sleep Quality Index. Sleep Med. 2011; 12: 70-5.

20. Gorenstein C, Andrade LHSG de. Inventário de depressão de Beck: propriedades psicométricas da versão em português. Arch Clin Psychiatry. 1998; 25: 245-50.

21. Cunha JA. Inventário de Depressão de Beck: Catálogo de técnicas úteis. In Cunha JA (org.). Psicodiagnóstico. 5ed. Porto Alegre: Artes Médicas; 2000.

22. Cunha JA. Manual da versão em português das Escalas de Beck. São Paulo: Casa do Psicólogo. 2001; 256: 11-3

23. Paiva ES, Heymann RE, Rezende MC, et al. A Brazilian Portuguese version of the Revised Fibromyalgia Impact Questionnaire (FIQR): A validation study. Clin Rheumatol. 2013; 32: 1199-206.

24. Stewart WF, Lipton RB, Dowson AJ, et al. Development and testing of the Migraine Disability Assessment (MIDAS) Questionnaire to assess headache-related disability. Neurology. 2001; 56: 20-8.

25. Matsudo S, Araújo T, Matsudo V, et al. Questionário Internacional de Atividade Física (IPAQ): estudo de validade e reprodutibilidade no Brasil. Rev Bras Ativ Fís Saúde. 2001; 6: 5-12.

26. Holroyd KA, Drew JB, Cottrell CK. Impaired functioning and quality of life in severe migraine: the role of catastrophizing and associated symptoms. Cephalalgia. 2007; 27: 1156-65.

27. McLoughlin MJ, Colbert LH, Stegner AJ. Are women with fibromyalgia less physically active than healthy women? Med Sci Sports Exerc. 2011; 43: 905-12.

28. Nijs J, Roussel N, Van Oosterwijck J, et al. Fear of movement and avoidance behaviour toward physical activity in chronic-fatigue syndrome and fibromyalgia: State of the art and implications for clinical practice. Clin Rheumatol. 2013; 32: 1121-9 